\title{
I promessi sposi: entre o cânone e a adaptação parodística na televisão italiana
}

\author{
Regina Farias de Queiroz \\ Universidade do Estado do Amazonas \\ rqueiroz@uea.edu.br
}

\begin{abstract}
RESUMO: Para discutir as questões subjacentes à adaptação de um texto clássico para as mídias, tomamos como objeto de estudo uma adaptação em formato de paródia para a televisão. I promessi sposi secondo il trio é uma minissérie em 5 episódios, realizada pela RAI, dirigida e protagonizada pelo trio LopezMarchesini-Solenghi, em 1990, que ganhou grande notoriedade nacional, exatamente pelo tom cômico que imprimiu à narrativa manzoniana. Neste trabalho, buscamos identificar as estratégias utilizadas na adaptação do clássico para a paródia e para tal, aplicamos ao texto televisivo parodístico o modelo prático-analítico de Robert Stam (2006), que concebe a adaptação audiovisual em dois níveis: estrutural e contextual. A partir dessa aplicação, utilizamos as categorias propostas pelo autor em todos os níveis de análise, a saber: autoria, personagens, narratologia, ordem, frequência e contexto. Os resultados demonstraram que as ressignificações proporcionadas pela adaptação televisiva ampliaram as possibilidades de interpretação do texto literário, além de consolidarem um processo de atualização de tal obra.
\end{abstract}

Palavras-chave: I promessi sposi. Literatura italiana. Televisão. Adaptação. Paródia.

ABSTRACT: Per discutere le questioni alla base dell'adattamento di un testo classico per i media, è stato preso come oggetto di studio un adattamento in parodia per la televisione. I promessi sposi secondo il trio è una mini-serie in 5 episodi, realizzata dalla RAI, diretta e interpretata dal trio Lopez-MarchesiniSolenghi nel 1990, la quale ha acquisito una grande notorietà nazionale proprio per il tono comico che ha impresso alla narrazione manzoniana. Il presente articolo ha cercato di individuare le strategie utilizzate nell'adattamento del classico in parodia, e, a tal fine, è stato applicato al testo televisivo parodistico il modello pratico-analitico di Robert Stam (2006), il quale concepisce l'adattamento audio-visivo in due livelli: strutturale e contestuale. Partendo da questa applicazione, si sono utilizzate le categorie proposte dall'autore in tutti i livelli di analisi, ovvero: paternità, personaggi, narratologia, ordine, frequenza e contesto. I risultati hanno dimostrato come i nuovi significati ottenuti attraverso l'adattamento televisivo abbiano ampliato le possibilità di interpretazione del testo letterario, oltre a consolidare un processo di aggiornamento di quest'ultimo. 
Parole-chiave: I promessi sposi. Letteratura italiana. Televisione. Adattamento. Parodia.

ABSTRACT: In order to discuss the issues underlying the adaptation for the visual media of a classic text, the object of study of the hereby article has been an adaptation, in the format of a parody for the television. I promessi sposi secondo il trio is a mini TV-series consisting of 5 episodes, created by the RAI, directed and interpreted by the trio Lopez-Marchesini-Solenghi in 1990, which gained great national notoriety precisely because of the comedy tone it imprinted on Manzoni's narrative.

The hereby research has tried to identify the strategies used to adapt the classic novel into a parody and, in order to do so, the practical-analytic model by Robert Stam (2006) have been applied to the TV parody text. Such model conceives audio-visual adaptation in two levels: structural and contextual, and applying it, the categories proposed by the author, which are: authorship, characters, narratology, order, frequency and context, have been used in all the levels of the analysis. The results proved how the new meanings obtained through the TV adaptation have widened the possibilities of interpretation of the written text, and have also consolidated a process of updating the novel. Keywords: I promessi sposi. Italian Literature. Television. Adaptation. Parody.

\section{Introdução}

$\mathcal{A}$ adaptação de livros para as telas é um fenômeno emergente nas sociedades contemporâneas. Isso teve início no cinema, mas logo ganhou espaço também na televisão. Olhando mais atentamente para as adaptações produzidas na televisão italiana, observamos uma predileção pelos clássicos no período dito paleotelevisione ${ }^{1}$ no qual foram produzidos os sceneggiati ${ }^{2}$, dos quais Sandro Bolchi foi o principal representante e dirigiu, entre outras produções, $I$ promessi sposi, ainda em preto e branco, em 1967. Já na neotelevisione e na atualidade, os clássicos cederam lugar à literatura de massa- entendida como literatura de mercado, que se opõe à literatura canônica. Somente no início da neotelevisione o clássico manzoniano ganhou uma releitura para a televisão, no formato de paródia. 
De modo sucinto, podemos definir paródia como um texto que mantém com outro uma relação de intertextualidade, sendo, portanto, uma repetição com elementos diferentes, construída por meio da comicidade e do ridículo. Para Hutcheon (1985, p.17) "[a] paródia é, pois, uma forma de imitação caracterizada por uma inversão irônica, nem sempre às custas do texto parodiado", o que a leva a demonstrar um tom de crítica em relação ao texto de partida. A partir disso, a "imutabilidade" do clássico passa a ser questionada na produção do trio Massimo Lopez, Anna Marchesini e Tulio Solenghi, devido à comicidade.

Nesse contexto, entendemos que as significações produzidas pela adaptação de um texto literário são estabelecidas por meio de um processo de negociação entre a autoria (entendendo neste caso a produção) e a audiência, dependendo, sobretudo, do contexto no qual foi produzido. Dessa maneira, neste trabalho, propomo-nos a verificar as estratégias utilizadas na adaptação da referida obra para a paródia.

\section{A adaptação de clássicos na televisão}

Conforme apresentado nas considerações iniciais, a adaptação de textos literários é uma prática frequente no cinema e na televisão. Logo, não apenas os best-sellers (mas também muitos clássicos) foram e continuam sendo adaptados para as telas. Para melhor entender esse cenário, apresentaremos a seguir alguns esclarecimentos no tocante aos aspectos teóricos das adaptações e, posteriormente, a definição dos clássicos.

Para Stam (2006, p.33), adaptações "são hipertextos derivados de hipotextos pré-existentes que foram transformados por operações de seleção, amplificação, concretização e efetivação”. Já para Hutcheon (2013, p.30), a adaptação é: "[u]ma transposição declarada de uma ou mais obras 
reconhecíveis; -um ato criativo e interpretativo de apropriação/ recuperação; um engajamento intertextual extensivo com a obra adaptada."

Como é possível observar, a autora (2013) apresenta três definições para a adaptação, a partir das quais considera esse processo como um "transporte" de textos (ou uma derivação, para Stam), como um processo de criação e interpretação e como um engajamento. Desse modo, compreendemos que a adaptação se estabelece em uma relação que vai do texto $\mathrm{A}$ ao texto $\mathrm{B}$, na qual o texto A, texto de partida (ou hipotexto), é interpretado (e transformado), ganhando outras significações a partir da criação de um outro texto, o texto de chegada (ou hipertexto). A criação deste último, que é exatamente o produto da adaptação, traz consigo a característica de engajar-se e atualizar-se no contexto em que foi produzido, por meio das escolhas e das estratégias do adaptador, motivadas por uma infinidade de questões, sejam elas políticas, econômicas, ideológicas ou de qualquer outra natureza.

Apesar das diversas questões envolvidas quando se trata de adaptação, essa foi vista, durante muito tempo, como uma arte menor e de menos valia que a literatura e, infelizmente, ainda hoje, em menores proporções, ainda é vista assim, principalmente a literatura considerada canônica. Essa literatura, por sua vez, é permeada de mitos em torno de seus clássicos, tais como a sacralidade e a imutabilidade, visto que são obras atemporais que fazem parte da memória coletiva de um povo e da sua história enquanto nação. Portanto, qualquer "mudança" gera impactos significativos e importantes para entender que as adaptações são produtos salutares nas mídias. Logo, vale pontuar o questionamento levantado por Hutcheon (2013, p.24): “[s]e as adaptações são, por definição, criações tão inferiores e secundárias, por que estão assim presentes em nossa cultura e, de fato, em número cada vez maior?”. Diante disso, convém destacar que adaptar um clássico é algo mais delicado do que 
adaptar um best-seller exatamente por conta da ideia de que um clássico não pode ser mexido.

Nas palavras de Calvino (1993, p. 11), "um clássico é um livro que nunca terminou de dizer aquilo que tinha para dizer". Nesse sentido, se uma obra nunca termina, ela sugere constantemente outras leituras e, consequentemente, outras significações. Essas significações podem ser resultantes do processo de adaptação, que envolve um ato criativo e engajado. Assim, são muitos os motivos para se realizar uma adaptação: reconstruir um personagem, destacar um elemento da narrativa ou até mesmo ironizar o texto de partida. Qualquer que seja o motivo ou a estratégia empregada pelo adaptador, é certo que a adaptação, de certa forma, promove o texto de partida e o seu autor, construindo novas "imagens" desse texto. Sobre isso, vale recorrer à citação de Lefevere (2007, p. 18-19), a qual afirma que:

no passado, assim como no presente, reescritores criam imagens de um escritor, de uma obra, de um período, de um gênero e, às vezes, de toda uma literatura. Essas imagens existiam ao lado das originais com as quais elas competiam, mas as imagens sempre tenderam a alcançar mais pessoas do que a original correspondente e, assim, certamente o fazem hoje.

Pensando, por exemplo, nos clássicos e na televisão, é conveniente ocorrer o processo de adaptação se considerarmos que muitos leitores conhecem os clássicos primeiramente por meio das suas adaptações, já que a televisão é dentre os veículos de comunicação de massa aquele de maior alcance e, portanto, "o meio hegemônico por excelência da segunda metade do século XX” (MACHADO, 2000, p. 15). E por alcançar tantas pessoas é possível criar múltiplas imagens de um autor.

\section{O clássico I promessi sposi e suas adaptações na televisão italiana}

A obra escrita por Manzoni é um dos maiores clássicos da Literatura italiana, ficando atrás apenas da Divina Commedia, de Dante Alighieri. O romance 
manzoniano passou por duas versões até chegar a sua terceira e última, entre 1840-1842, e se insere no Romantismo italiano. Todavia, vale esclarecer que, apesar da trama tipicamente romântica, o romance não é uma representação literária do amor. Ao contrário, Manzoni concentra-se nos episódios sociais, de natureza historiográfica, analisando-os e dissertando sobre eles.

O autor descreve uma sociedade violenta, marcada pelo embate de classes. Resumidamente, o romance narra os acontecimentos em torno da proibição do casamento de Renzo Tramaglino e Lucia Mondella, um casal que vivencia muitos sofrimentos e dolorosas experiências das mais variadas espécies. Os noivos que protagonizam o romance são tecelões iletrados, moradores de Lecco, uma pequena vila na Lombardia, entre 1628 e 1632. Os dois são impedidos de se casar por conta de Don Rodrigo, um fidalgo devasso que aposta com seu primo a conquista de Lucia.

Apesar de clássico, I promessi sposi mantém relações com a atualidade, na medida em que adota, de maneira inovadora, o discurso de revolta e opressão de uma sociedade humilhada pelos poderosos. Sobre essa obra, Enei (2010, p. 276) declara que “[é] a obra mais significativa do século XVIII na Itália. Impõe moral, bem, Deus, não-Deus, heróis, vencidos e vencedores, chegando a recolher essas notas diferentes numa sinfonia que é a explicação da realidade".

Devido à popularidade e à notoriedade do texto de Manzoni, muitas adaptações foram feitas a partir dessa obra para os mais diversos formatos de mídia. No caso específico da televisão, a obra ganhou três adaptações na Rai, em formato de minissérie, e uma adaptação no Canale 5, também como minissérie. Neste trabalho, detemo-nos, brevemente, apenas às adaptações produzidas pela Rai. A primeira adaptação da emissora para o romance manzoniano data de 1967, ainda em preto e branco, e foi dirigida por Sandro Bolchi. Essa minissérie com 8 episódios tinha um caráter didático próprio do período histórico televisivo no qual se inseriu, pois, naquela época, a Rai 
intentava divulgar os clássicos literários para servir de modelo de língua e literatura aos telespectadores italianos.

Já a segunda produção da emissora, em 5 episódios, com direção de Salvatore Nocita, foi ao ar em 1989. Portanto, já em cores e marcando um novo período da história da televisão italiana: a passagem da paleotelevisione para a neotelevisione. Sobre essa mudança na história da televisão italiana, Scaglioni (2013, p. 47) comenta: “O advento da televisão comercial, na Itália, nos anos oitenta, representa de maneira simbólica as complexas transformações no universo cultural nacional daquela década e daquelas imediatamente sucessivas. ${ }^{4}$

Mais adiante, na mesma página, o autor diz ainda que: “[...] a televisão comercial desenha os traços de um entretenimento puro, concebido industrialmente, 'sem culpa' e sem necessidade de justificativas intelectuais"'5. Dessa maneira, tais afirmações nos conduzem a pensar que nesse percurso feito pela televisão a Rai, na qualidade de primeira emissora de televisão da Itália, começou a redefinir novos espaços e a repensar a sua programação.

Por isso, ao contrário de uma televisão pública, moldada nos interesses políticos e controlada por valores católicos, como era na paleotelevisione, a Rai assumiu, na neotelevisione, uma posição muito mais liberal com relação aos conteúdos transmitidos na sua rede de programação e mais próxima dos ideais comerciais. Assim, para delimitar esse novo período, logo em seguida, em 1990, o trio cômico Massimo Lopez, Anna Marchesini e Tulio Solenghi produziu a terceira minissérie em formato de paródia, também em 5 episódios, chamada $I$ promessi sposi: da un'idea di Alessandro Manzoni, que satirizava o texto manzoniano e questionava os mitos em torno da sacralidade do clássico.

\section{Metodologia e análise do corpus}

Para Hutecheon (2013), são várias as possibilidades metodológicas que podem ser aplicadas à análise de adaptações audiovisuais e cabe ao pesquisador 
aquela mais adequada aos objetivos da sua pesquisa. Partindo desse pressuposto, trabalharemos com Stam (2006), que propõe um modelo específico para a análise de adaptações audiovisuais a partir da retomada do conceito de "transtextualidade", proposto por Genette (1982). Segundo tal conceito, existem cinco tipos de relações transtextuais: intertextualidade ou efeito de co-presença entre dois textos (citação, plágio e alusão-intertexto); paratextualidade (paratexto); metatextualidade (relação crítica); arquitextualidade. Para atender aos propósitos deste trabalho, interessa-nos apenas a última relação, a hipertextualidade, a qual toma como hipertexto o texto fonte e como hipotexto, o texto adaptado.

O modelo de análise proposto por Stam (2006) elenca três grandes categorias de análise do hipertexto: análise estrutural, análise contextual e narratologia comparativa. A primeira categoria apresenta três elementos: autoria, personagem e narratologia, sendo que a narratologia, por sua vez, subdivide-se em: ordem, duração e frequência. Já a segunda categoria, por sua vez, apresenta: contexto temporal, censura, ideologia, inserção em uma época anterior ou atualização e cenário nacional ou transnacional. Por fim, a terceira categoria apresentada pelo autor é a narratologia comparativa, que se baseia na permuta e nas modificações da história e do contexto. Nessa categoria, perguntas do tipo "o que foi retirado, acrescentado ou modificado no texto adaptado?” se fazem necessárias e são de elevada importância para a análise. Dessa forma, observam-se como os personagens são modificados e qual o sentido dessas modificações. Sobre esse modelo de análise, o autor esclarece:

Finalmente, gostaria de fazer algumas propostas modestas para lidar com a narrativa, aspectos temáticos e estilísticos das adaptações cinematográficas, algo menos grandiosamente ambicioso do que uma teoria, porém mais do que uma metodologia. Aqui eu não estarei mais tratando do status teórico da adaptação, mas sim posicionando um modelo prático/analítico para tratar adaptações das propriamente ditas (STAM, 2006, p.35). 
É importante frisar que o trabalho com textos de época, como é o caso das literaturas canônicas, envolve, muitas vezes, estratégias de atualização, ou seja, inserção da obra em uma época diferente. Assim como Hutcheon (2013), que considera as adaptações como produtos de atualização, Stam (2006, p. 45) também corrobora com essa ideia ao afirmar que:

adaptações de romances de outros períodos confrontam o cineasta com a escolha de criar um drama de época ou atualizar o romance para o período contemporâneo. Obras de época apresentam desafios especiais, não apenas em termos de reconstruir uma era, mas também em termos de evitar anacronismos temporais tais como antenas de TV na Inglaterra vitoriana ou aviões nos céus da França revolucionária.

Apresentadas as considerações de Stam para a análise de adaptações audiovisuais, propomos, a seguir, a aplicação de seu quadro metodológico à análise, em termos, da minissérie I promessi sposi. Para tanto, assistimos ao primeiro DVD da minissérie, a fim de identificar cada uma das categorias presentes na proposta do autor (análise estrutural, análise contextual e narratologia comparativa e suas subcategorias).

O material analisado neste artigo foi o primeiro de dois DVDs produzidos e distribuídos pela Rai, em 1990 e comercializados sob o título: I promessi sposi: da un'idea di Alessandro Manzoni. A adaptação é de autoria do trio Massimo Lopez, Anna Marchesini e Tulio Solenghi.

Inicialmente, no tocante aos personagens, ocorreu um acréscimo em relação ao texto de Manzoni, de modo que passaram a compor o elenco os seguintes personagens: o narrador (que interage com os demais personagens), o pai de Lucia, o irmão de Lucia (Lucio), Alessandro Manzoni (em forma de aparição, como o fantasma do autor já morto), Bella Figueira (namorada de Don Rodrigo) e a repórter. Além dos acréscimos, observa-se também a caracterização de personagens já conhecidos do público, tanto por meio da leitura do livro, quanto por meio das adaptações anteriores produzidas pela Rai. Nesse caso, o personagem Don Abbondio, por exemplo, é estereotipado como 
um homem extremamente medroso, chegando ao ponto de ser comparado a um cão, fato que endossa, inclusive, o tom humorístico da minissérie. Já Frei Cristoforo, outro personagem central para a trama, é descrito como um roqueiro, o que faz certa alusão à descrição manzoniana da sua juventude mais rebelde. Na época de Manzoni, um jovem rebelde duelava com espadas para demonstrar poder, domínio de território ou simplesmente pelo prazer de medir forças com outro jovem. Essa característica de rebeldia foi traduzida na paródia televisiva por meio da construção de um personagem roqueiro porque, nos anos 80, a rebeldia era um traço típico dos roqueiros. Levando em consideração que a paródia da Rai foi ao ar em 1990, podemos considerar que esse estereótipo ainda fosse algo bem marcado na sociedade.

No que diz respeito à narratologia, é importante ter em mente que a minissérie pertence ao gênero paródia. Assim, não falamos de uma ordem muito linear, visto que muitos elementos novos são inseridos na trama. O primeiro DVD, cujo conteúdo é analisado aqui, tem duração de 110 minutos e corresponde aos dois primeiros episódios e a metade do terceiro.

Para a análise contextual, convém, primeiramente, analisar o contexto de produção, que data de 1990. Houve um esforço para reproduzir o figuro, os costumes e até a linguagem da época retratada (século XVII), mas sempre com um tom de crítica e caricatura, seja ao texto literário, seja às adaptações fílmicas e televisivas que a antecederam. Essa junção entre o antigo e o novo, manifestada no processo de atualização do hipotexto, pode ser observada também nos figurinos, visto que, ora os atores aparecem vestidos com roupas de época - para se aproximarem da época retratada no romance -, ora aparecem com roupas usuais nos anos 90 - caso do traje de atleta, usado por Renzo, em uma cena que marca uma maratona de corrida.

No que diz respeito à censura, vale pontuar dois momentos muito emblemáticos na paródia. Um deles mostra Renzo tocando o seio de Agnese, 
sua futura sogra; já em outra cena, Frei Cristoforo aparece dançando rock com uma guitarra nas mãos, o que seria considerado algo desapropriado, dentro do contexto de recepção da série, para um religioso.

Analisando o discurso social e a ideologia presentes no primeiro DVD, devemos salientar que essa produção faz uso constante da metalinguagem, pois muitas das cenas fazem referência direta à linguagem televisiva. Um exemplo dessa situação ocorre em uma citação a Maurizio Costanzo e Mike Buongiorno, apresentadores dos primórdios da Rai. A paródia dessa emissora, conforme já exposto, faz críticas às adaptações anteriores. É o que ocorre, por exemplo, em uma referência à atriz Dina Sassoli, intérprete de Lucia no filme I promessi sposi, de Mario Camerini, em 1941, devido à sua interpretação exagerada, marcada pela construção das suas expressões faciais. Para demonstrar isso, Anna Marchesini, intérprete de Lucia na paródia, arregala os olhos e abre bastante a boca, de modo a fazer uma caricatura das expressões faciais de Dina Sassoli.

Outro ponto importante a ser observado é a preocupação que a paródia teve em mostrar que o texto literário não é intocável e, nesse sentido, os atores dialogam frequentemente com as câmeras, como se falassem diretamente com o público para explicar que não há nada de errado em parodiar um texto canônico. Essa preocupação demonstra que, na época em que foi produzida a minissérie (1990), ainda existia o culto à fidelidade e à essência da obra. Então, provavelmente, na tentativa de evitar críticas pesadas à produção da Rai, os próprios atores tenham tentado se aproximar de seus telespectadores para desmistificar a "intocabilidade" e "imutabilidade" do texto clássico.

O próximo item da categoria análise contextual diz respeito à inserção em uma época anterior ou atualização. Por ser uma paródia, a minissérie mescla o tempo passado com o tempo presente e, portanto, nesse enquadramento, a maioria das cenas apresentam figurinos antigos. Contudo, em alguns momentos aparecem figurinos atuais, como no caso do maiô usado pela Miss Lecco e do 
terninho da jornalista. O mesmo ocorre com a linguagem usada pelos atores, que durante a maior parte do tempo utilizam construções sintáticas e lexicais iguais às do texto literário, mas carregadas de um tom caricatural, a fim de não cansar o telespectador com o italiano antigo do romance. Acrescenta-se, ainda, a inserção de alguns objetos atuais, como o telefone e a televisão. Com relação aos cenários retratados na minissérie, por sua vez, pode-se dizer que as cenas se passam em estúdio fechado, geralmente com uma única focalização da câmera.

A adaptação aqui analisada é a única minissérie televisiva produzida no gênero paródia e a primeira que rompeu com a preocupação exacerbada da fidelidade ao original, vista nas adaptações anteriores. A minissérie do trio tem poucos cenários e pouco jogo de câmera, se comparada às outras produzidas pela mesma emissora, o que deixa as cenas muito mais próximas a uma produção teatral. Junte-se a isso também a mescla entre os gêneros paródia e musical. Em várias cenas, os atores criam paródias musicais de curta duração para contar eventos do enredo ou caracterizar alguns personagens.

Por se tratar de uma paródia, essa é a minissérie que mais apresenta relações intertextuais e isso ocorre pela metalinguagem de forma direta, quando os atores comentam sobre adaptações anteriores e de forma indireta, por meio do figurino adotado pelos atores. Para exemplificar esse último caso, basta mencionar a coroa da qual faz uso a personagem Lucia, muito parecida com a coroa adotada na primeira adaptação de I promessi posi realizada pela Rai, em 1967, com o propósito de ridicularizar esse acessório. Esse objetivo de satirizar as primeiras adaptações do romance, tanto no cinema - com o filme de Camerini (1941) -, quanto na televisão - com a minissérie de Bolchi (1967) -, fica evidente quando a narradora da trama pede a Renzo para que ele se esforce mais para atingir expressões faciais exageradas, tanto quanto faziam os atores nas adaptações audiovisuais precedentes. 


\section{Considerações finais}

Este trabalho teve a finalidade de apresentar, brevemente, a minissérie $I$ promessi sposi: Da un'idea di Alessandro Manzoni, protagonizada e dirigida pelo trio Massimo Lopez, Anna Marchesini, Tullio Solenghi, veiculada na Rai, em 1990. Dentro dessa breve apresentação, buscamos evidenciar as estratégias utilizadas no processo de adaptação de um texto clássico para a paródia e a partir do uso de tais estratégias.

Dentre as estratégias usadas na adaptação do clássico manzoniano, destacamos o acréscimo e a releitura de personagens nos moldes de 1990, período no qual a adaptação foi exibida pela Rai. Dos personagens incluídos na adaptação parodística, o que mais chamou a atenção foi o próprio autor do romance, Alessandro Manzoni, ao aparecer em forma de fantasma para discordar das escolhas dos adaptadores (o que reforça o tom humorístico da produção televisiva). Além da figura do autor, vale destacar a presença de dois narradores que conduzem os telespectadores de modo explícito, a construção de uma crítica direcionada ao livro e às adaptações audiovisuais antecessoras a essa; o que cumpre exatamente com o propósito do gênero paródia. Apesar de a paródia trazer no seu conteúdo a comicidade aliada à crítica, a minissérie televisiva aqui analisada demonstrou, ainda, certo receio em ironizar o hipotexto por parte dos adaptadores dessa obra em alterar ou até mesmo "brincar" com o texto de partida. Todavia, a iniciativa de adaptar para a televisão em formato de paródia o clássico manzoniano pela primeira vez foi muito importante para começar a desmistificar os preconceitos em torno das adaptações dos textos canônicos.

\footnotetext{
${ }^{1}$ Os termos paleotelevisione e neotelevisione, de modo geral, são comumente usados nos estudos de televisão italiana para se referirem, respectivamente, ao período de surgimento da televisão, pautada no serviço público, e ao período que marca a passagem da televisão pública para a televisão comercial.

2 Denominam-se sceneggiati as primeiras adaptações televisivas de textos literários canônicos, produzidas pela Rai, canal de Tv italiano.

3 Ver nota 1.
} 
${ }^{4}$ L'avvento della televisione commerciale, in Italia, negli anni Ottanta, rappresenta in maneira simbólica $\mathrm{i}$ complessi mutamenti nell'universo culturale nazionale di quel decennio, e di quelli imediatamente successivi. Tradução de nossa autoria, assim como as demais não referenciadas neste trabalho (SCAGLIONI, 2013, p. 47).

5 [...] la televisione commerciale disegna i tratti di un intrattenimento puro, industrialmente concepito, senza 'sensi di colpa' e senza necessità di giustificazioni intellettuali (SCAGLIONI, 2013, p. 47).

\section{Referências}

CALVINO, Italo. Por que ler os clássicos. Trad.: Nilson Moulin. São Paulo: Companhia das Letras, 1993.

ENEI, Bruno. Aulas de literatura italiana e desafios criticos. Ponta Grossa: Toda palavra, 2010.

GENETTE, Gerard. Palimpsestos: a literatura de segunda mão. Tradução de Luciene Guimarães e Maria Antônia Ramos Coutinho. UFMG: Faculdade de Letras, [1982] 2010.

HUTCHEON, Linda. Uma teoria da paródia: ensinamentos das formas de arte do século XX. Trad. de Tereza Louro Pérez. Lisboa: Edições 70, 1985.

- Uma teoria da adaptação. $2^{\mathrm{a}}$ ed. Trad. André Cechinel. Florianópolis: Ed. UFSC, 2013.

I PROMESSI SPOSI: da un'idea di Alessandro Manzoni (1990). Direção: Massimo Lopez, Ana Marchesini, Tuglio Solenghi. Produção: Rai- Eri, Itália, 2012. DVD duplo.

LEFEVERE, André. Traducão, reescrita e manipulação da fama literária. Trad. Claudia Matos Seligmann. Bauru, SP: Edusc, 2007.

MACHADO, Arlindo. A tv levada a sério. São Paulo: Editora SENAC, 2000.

STAM, Robert. Teoria e Prática da Adaptacão: da fidelidade à intertextualidade. In: Ilha do Desterro. Florianópolis, 2006. p.19-53. 